Research Article

\title{
Prevalence of Type 2 Diabetes and Hypertension: Opportunistic Screening in Delhi
}

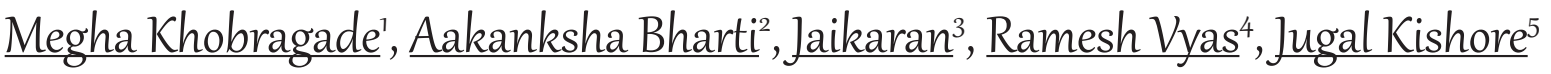 \\ ${ }^{1}$ ADG (Leprosy), MoHFW, Government of India. \\ ${ }^{2}$ Department of Community Medicine, VMMC and Safdarjung Hospital, New Delhi. \\ ${ }^{3}$ Deputy Director, National Center for Disease Control, MoHFW, Government of India. \\ ${ }^{4}$ Joint Director, GIMS, Greater Noida, U.P., India. \\ ${ }^{5}$ Director Professor \& Head of Department of Community Medicine, VMMC \& Safdarjung Hospital, New Delhi. \\ DOI: https://doi.org/10.24321/2349.7181.201913
}

\section{I $\quad \mathbf{N} \quad \mathbf{F} \quad \mathbf{O}$}

\section{Corresponding Author:}

Aakanksha Bharti, Department of Community Medicine, VMMC and Safdarjung Hospital, New Delhi.

E-mail Id:

aakanksha.bharti@gmail.com

\section{Orcid Id:}

https://orcid.org/0000-0002-8851-8925

How to cite this article:

Khobragade M, Bharti A, Jaikaran, Vyas R, Kishore J. Prevalence of Type 2 Diabetes and Hypertension: Opportunistic Screening in Delhi. J Adv Res Med 2019; 6(3): 8-11.

Date of Submission: 2019-12-10

Date of Acceptance: 2019-12-30

\section{$\begin{array}{lllllllllllllll}\mathbf{A} & \mathbf{B} & \mathbf{S} & \mathbf{T} & \mathbf{R} & \mathbf{A} & \mathbf{C} & \mathbf{T}\end{array}$}

Introduction: Type 2 Diabetes and Hypertension are the two NonCommunicable Diseases (NCDs) that are on an increasing trend both at the global and national level. It has also been estimated that the prevalence of both the NCDs in India will be increasing further in the future. A better understanding and management of both diabetes and hypertension, which can be done by dietary changes and lifestyle modifications, would help in reducing cardiovascular mortality in India.

Methods: An opportunity was created while running a screening facility organised on the occasion of Ambedkar Jayanti 14th April, 2019 in Delhi. All consented individuals attending the screening camp who were 30 years or more of age were included in the study. Three Blood Pressure readings were taken and random blood sugar was measured for all the attending individuals, to diagnose hypertension and diabetes respectively. History regarding previously diagnosed hypertension and diabetes was also taken. The data was entered in a master sheet on MS Excel and later transferred from MS Excel to SPSS licensed Software version 20.0 for analysis.

Result: A total of 214 individuals aged 30 years or more were screened for Type 2 Diabetes and Hypertension, among them there were $78 \%$ $(n=167)$ males and $22 \%(n=47)$ females among the screened individuals. About $27 \%(n=47)$ of the screened individuals had raised systolic blood pressure, and $33 \%(n=53)$ had raised diastolic blood pressure. The mean systolic blood pressure was $130.49 \pm 21.7 \mathrm{mmHg}$ and mean diastolic blood pressure was $85.72 \pm 12.6 \mathrm{mmHg}$. Nearly half $(50.7 \%, n=73)$ of those screened had raised random blood sugar. Approximately $19 \%$ $(n=41)$ of the individuals reported to have diagnosed Type 2 diabetes and hypertension and were on treatment.

Conclusion: This study found a high percentage of individuals with increased blood sugar and blood pressure, ascertaining the need of opportunistic screening as a part of routine activity.

Keywords: Hypertension, Diabetes, Screening, NCD 


\section{Introduction}

Type 2 diabetes and hypertension, both are on increasing trend in India due to major epidemiological transition. Both are responsible for immense morbidity and economic losses at family and the national level. According to National Family Health Survey (NFHS-4) the prevalence of diabetes was found to be $6.85 \%$ and hypertension as $8.5 \%$ in general population. Deaths resulting from non-communicable diseases are expected to increase their share of the total from 55 per cent in 1990 to 73 per cent in $2020 .^{1}$

Due to reasons like rapid urbanisation, adopting sedentary life style and an increase in the ageing population in India, the prevalence of both diabetes and hypertension is expected to increase further. It has been predicted that almost 87 million people in India will be having diabetes by the year $2030 .{ }^{2} \mathrm{~A}$ better understanding and management of both diabetes and hypertension, which can be done by dietary changes and lifestyle modifications, would also help in reducing cardiovascular mortality in India. In addition, both these conditions are comorbid. The prevalence of hypertension is 1.5 to 2.0 times more in those with diabetes than in those without diabetes, whereas almost one-third of the patients with hypertension develop diabetes later. ${ }^{3}$

It has been found that approximately half of the people with diabetes and hypertension remain undiagnosed and untreated, and may develop complications during that time. Timely diagnosis, which can be achieved through screening and treatment along with compliance in patients with diabetes and hypertension, can prove to be a turning point in the course of the disease. There are a number of factors that affect the prognosis of both the diseases, but some of the major factors remain treatment compliance and prevention of complications.

However, primary prevention strategies, like screening would play a pivotal role in controlling this global epidemic. All attempts should be made to detect the problem as early as possible beside risk factor reduction. The present study was carried out with the objective to screen all the individuals attending public camp for Type 2 diabetes and hypertension and find out their treatment compliance if already diagnosed.

\section{Methods}

An opportunity was created while running a screening facility organised by Bahujan Ekta Manch in collaboration with Rashtriya Samagra Vikas Sangh, (RSVS) on the occasion of Ambedkar Jayanti 14th April, 2019 in Delhi. One of the objectives of RSVS is creating free and holistic healthcare system.

All individuals attending the screening camp, who gave their consent and were 30 years or more of age were included in the study. Blood pressure was measured three times by automated electronic device (Omron HEM) with individual sitting comfortably on the chair. Average of the three readings was taken for final recording. Random blood sugar was also measured for all the participants using glucometer under safety precautions. History of known case of diabetes and hypertension was collected. Questions on whether they were on treatment and adhered to it were also asked. All those who were found to have high blood pressure and increased random blood sugar were referred to the nearest hospital for confirmation of diagnosis by fasting post-prandial blood glucose or measurement of HBA1C in case of diabetes and blood pressure charting in case of hypertension as well as for starting of treatment.

Participants were diagnosed as having raised blood sugar when random blood sugar was more than or equal to 140 $\mathrm{mg} / \mathrm{dL} .{ }^{4}$ Raised blood pressure was labelled when systolic blood pressure was more than equal to $140 \mathrm{mmHg}$ or diastolic blood pressure was more than or equal to 90 mmHg. ${ }^{5}$

The data was entered in a master sheet on MS Excel and later transferred from MS Excel to SPSS licensed Software version 20.0 for analysis. Simple tables and cross tables were made to present the data.

\section{Result}

A total of 214 individuals attended the camp and were screened for Type 2 diabetes and hypertension. There were $78 \%(n=167)$ males and $22 \%(n=47)$ females among the screened individuals.

Table I.Distribution of study participants according to measured blood pressure

\begin{tabular}{|c|c|c|c|}
\hline $\begin{array}{c}\text { Blood } \\
\text { pressure }\end{array}$ & & Number & Percentage (\%) \\
\hline \multirow{3}{*}{ Systolic } & $<140$ & 117 & 73 \\
\hline & $141-160$ & 32 & 20 \\
\hline & $>161$ & 15 & 7 \\
\hline \multicolumn{2}{|c|}{ Total } & 160 & 100 \\
\hline \multirow{3}{*}{ Diastolic } & $<90$ & 107 & 67 \\
\hline & $91-100$ & 30 & 19 \\
\hline & $>101$ & 23 & 14 \\
\hline \multicolumn{2}{|c|}{ Total } & 160 & 100 \\
\hline
\end{tabular}

Complete blood pressure recording was made for 160 individuals. For 54 participants either one or two readings were missing. Around one third (27\%) of the screened individuals had raised systolic blood pressure and $33 \%$ had raised diastolic blood pressure. The mean systolic blood pressure was $130.49 \pm 21.7 \mathrm{mmHg}$ and mean diastolic blood pressure was $85.72 \pm 12.6 \mathrm{mmHg}$. 
Table 2.Distribution of study participants according to measured random blood sugar

\begin{tabular}{|c|c|c|}
\hline $\begin{array}{c}\text { Random blood } \\
\text { sugar }(\mathbf{m g} / \mathbf{d L})\end{array}$ & Frequency & Percentage \\
\hline$<140$ & 71 & 49.3 \\
\hline$>140$ & 73 & 50.7 \\
\hline Total & 144 & 100 \\
\hline
\end{tabular}

Table 2, shows random blood sugar of 144 individuals. For 70 participants, blood sugar testing was not done due to various reasons. Nearly half $(50.7 \%)$ of those screened had raised random blood sugar.

Approximately $19 \%(n=41)$ of the individuals reported to have already diagnosed Type 2 diabetes and hypertension and were currently on treatment.

\section{Discussion}

Out of the total 214 individuals, the proportion of males and females was $78 \%$ and $22 \%$ in the current study. Similar results were found in a study conducted by Dyavarishetty ${ }^{6}$ et al. in Mumbai where males comprised $79 \%$ of the sample and females $21 \%$. Although in a study ${ }^{7}$ conducted for screening at a workplace in India, the representation of males in the sample was $39 \%$ and that of females was as high as $61 \%$, this can be explained due to wide difference in the study setting.

In this study $27 \%$ of the participants had raised systolic blood pressure and $33 \%$ had raised diastolic blood pressure. Slightly lower prevalence was found in a community-based screening in Kenya, conducted by Pastakia et al., ${ }^{8}$ where $18 \%$ had raised systolic blood pressure and $15 \%$ had raised diastolic blood pressure. This difference can be due to difference in prevalence rates of the two countries and also due to screening done in the community-based setting. Ketkar et al. ${ }^{7}$ has found in their study that the prevalence of hypertension was $13 \%$ in individuals in healthcare setting. Geldsetzer et al. ${ }^{9}$ found $26.5 \%$ prevalence of hypertension in their study carried out across India.

The mean systolic and diastolic blood pressure in the current study was $130.49 \pm 21.7$ and $85.72 \pm 12.6$, respectively. Joshi et $\mathrm{al}^{10}$ in their study at the national level in India found the mean systolic and diastolic BP of patients as $128.8 \pm 15.9$ $\mathrm{mmHg}$ and $82.5 \pm 8.9 \mathrm{mmHg}$, respectively, which is little less than the results of the current study. Also, similar results were found in a study ${ }^{8}$ conducted in Kenya for screening of diabetes and hypertension, in which the mean systolic blood pressure was $125 \pm 19.28$ and diastolic was $77 \pm 13$.

Approximately half $(50.7 \%)$ of the screened individuals were found to have raised blood sugar in the present study. Screening India's Twin Epidemic (SITE) study ${ }^{10}$ found similar results, where prevalence of diabetes was $34.7 \%$. Contrasting results were found in western Kenya, ${ }^{8}$ where prevalence of diabetes was $23 \%$ and also the prevalence was only $7.6 \%$ in a national representative study conducted in India. ${ }^{9}$

There were many limitations of the study: screening in a mela or event may not be suitable place to detect the prevalence. The individuals could only be diagnosed as having raised blood sugar or raised blood pressure, as these are not the confirmatory tests. Only those who have higher risk of developing disease prefer to be tested to rule out their apprehension. It could be the reason for higher percentage of individuals with raised blood sugar and blood pressure in the study.

\section{Conclusion}

This study found a high percentage of individuals with increased blood sugar and blood pressure, ascertaining the need of opportunistic screening as a part of routine activity. Such screening camps help in identification of disease burden as well as in providing adequate referral linkage in order to facilitate early diagnosis and treatment and thus promoting secondary prevention as well.

It is recommended that such opportunistic screening may be carried out at regular intervals, and appropriate follow up of the referred individuals should be carried out particularly for non-communicable diseases.

Ethical Clearance: The study has been done by the data collected after a screening health camp. While screening, consent was taken from each individual and and the tests were done by each subject's willingness. We have analysed the data that was hence collected. Therefore no ethical clearance has been taken.

\section{Conflicts of Interest: None}

\section{References}

1. Murray CJL, Lopez AD. The Global Burden of Disease. A comprehensive assessment of mortality and disability from diseases, injuries and risk factors in 1990 and projected to 2020. (GBD Series Vol. I. Harvard School of Public Health on behalf of the World Health Organization and the World Bank, Cambridge, Massachusetts, 1996). Available From: https://apps. who.int/iris/handle/10665/41864.

2. Shaw JE, Sicree RA, Zimmet PZ. Global estimates of the prevalence of diabetes for 2010 and 2030. Diabetes Res Clin Pract 2010; 87(1): 4-14. Available From: https:// www.diabetesresearchclinicalpractice.com/article/ S0168-8227(09)00432-X/fulltext [PubMed/ Google Scholar].

3. Sahay BK. API-ICP guidelines on diabetes 2007. J Assoc Physicians India 2007; 55: 1-50. Available From: http:// 
www.japi.org/july2007/IDGM.pdf [Google Scholar].

4. Somannavar S, Ganesan A, Deepa M, Datta M, Mohan V. Random capillary blood glucose cut points for diabetes and pre-diabetes derived from communitybased opportunistic screening in India. Diabetes care 2009; 32(4): 641-643. Available From: https://care. diabetesjournals.org/content/32/4/641.long [PubMed/ Google Scholar].

5. Mahajan R. Joint National Committee 8 report: How it differ from JNC 7. International Journal of Applied and Basic Medical Research 2014; 4(2): 61-62. Available From: http://www.ijabmr.org/article.asp?issn=2229516X; year=2014; volume=4;issue=2; spage=61; epage =62; aulast=Mahajan [Google Scholar].

6. Dyavarishetty P, Kowli S. Population based screening for diabetes: experience in Mumbai slums, Maharashtra, India. Int J Res Med Sci 2016; 4(7): 2766-2769. Available From: https://pdfs.semanticscholar.org/ f867/c6c7f5d95c88b78339797c562b6eeea680d7.pdf [Google Scholar].

7. Ketkar AR, Veluswamy SK, Prabhu N, Maiya AG. Screening for noncommunicable disease risk factors at a workplace in India: A physiotherapy initiative in a healthcare setting. Hong Kong Physiotherapy Journal 2015; 33(1): 3-9. Available From: https://core.ac.uk/ download/pdf/81985382.pdf [Google Scholar].

8. Pastakia SD, Ali SM, Kamano JH, Akwanalo CO, Ndege SK, Buckwalter VL, Vedanthan R, Bloomfield GS. Screening for diabetes and hypertension in a rural low income setting in western Kenya utilizing homebased and community-based strategies. Globalization and health 2013; 9(1): 21.

9. Geldsetzer P, Manne-Goehler J, Theilmann M, Davies JI, Awasthi A, Vollmer S et al. Diabetes and hypertension in India: a nationally representative study of 1.3 million adults. JAMA internal medicine 2018; 178(3): 363-372.

10. Joshi SR, Saboo B, Vadivale M, Dani SI, Mithal A, Kaul $U$ et al. Prevalence of diagnosed and undiagnosed diabetes and hypertension in India-results from the Screening India's Twin Epidemic (SITE) study. Diabetes technology \& therapeutics 2012; 14(1): 8-15. 